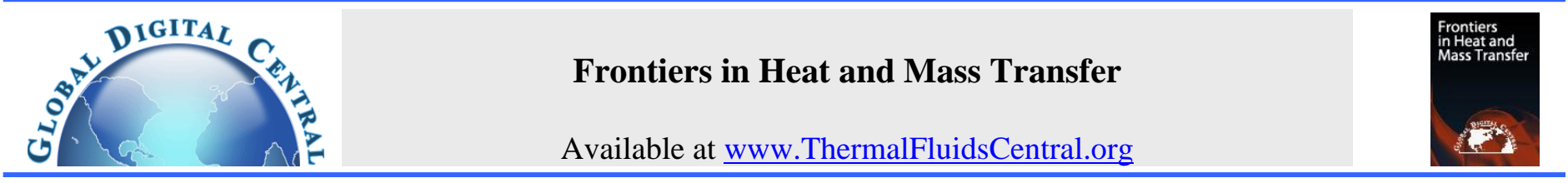

\title{
SOLUTE TRANSPORT AND HEAT TRANSFER IN SINGLE-PHASE FLOW IN POROUS MEDIUM WITH GENERATIVE/DESTRUCTIVE CHEMICAL REACTION AND VARIABLE VISCOSITY IMPACTS
}

\author{
Driss Achemlal ${ }^{\mathrm{a}, \dagger}$, Mohammed Sriti ${ }^{\mathrm{b}}$, Mohamed El Haroui ${ }^{\mathrm{b}}$, Elyazid Flilihi ${ }^{\mathrm{b}}$, Mounir Kriraa ${ }^{\mathrm{a}}$ \\ ${ }^{\mathrm{a}}$ National School of Applied Sciences - Al Hoceima, Civil Engineering and Energetics Department, Box : 03, Ajdir - Al Hoceima, Frist Mohammed \\ University, Morocco \\ ${ }^{\mathrm{b}}$ Engineering Sciences Laboratory, Polydisciplinary Faculty of Taza, Box : 1223 - Taza, Sidi Mohamed Ben Abdellah University, Morocco
}

\begin{abstract}
In this paper we study the combined free convection, due to thermal and species diffusion, of a viscous incompressible non Newtonian fluid over a vertical plate embedded in a saturated porous medium with three thermal states of the surface and a constant concentration in the presence of a chemical reaction. The effect of temperature dependent viscosity is also investigated. The Ostwald-de Waele power-law model is used to characterize the non-Newtonian fluid behavior. The governing boundary layer equations along with the boundary conditions are first cast into a dimensionless form by a unique similarity transformation and the resulting coupled differential equations are then solved numerically by a computational program based on the fifth order Runge-Kutta scheme with shooting iteration technique. The results are illustrated and the physical aspect is discussed for temperature and concentration profiles, as well as the Nusselt and Sherwood numbers for various values of the parameters, which govern the problem.
\end{abstract}

Keywords: dual-diffusion convection, non-Newtonian fluid, porous medium, chemical reaction

\section{INTRODUCTION}

The behavior of non-Newtonian fluids such as molten plastics, polymers, pulps, foods and slurries exhibits a non-linear relationship between shear stress and velocity gradients. Several mathematical models have been proposed to explain the rheological behavior of these fluids. Among these, a model which has been most widely used for non-Newtonian fluids, and is frequently encountered in chemical engineering processes, is the power law model. It has been successfully applied to non-Newtonian fluids experimentally.

The heat and mass transfer for non-Newtonian fluids in porous media, in general, is of great pragmatic importance in a wide variety of scientific and engineering applications such as geothermal fields, fibrous insulation, oil recovery, food processing, spreading of chemical contaminants through water-saturated soil and many others. The growing need for chemical reactions in chemical engineering and hydrometallurgical industries requires the study of heat and mass transfer with chemical reaction.

A comprehensive review of the literature concerning double-diffusive natural convection in a fluid saturated porous media can be found in the review article of Trevisan and Bejan (1990) and in the recent book of Nield and Bejan (2017).

The influence of melting on mixed convection heat and mass trans- fer from the vertical flat plate in a non-Newtonian nanofluid saturated porous medium is studied by Kairi and RamReddy (2015). Here, the wall and the ambient medium are maintained at constant, but different, levels of temperature and concentration. It was noted that the temperature and concentration profiles as well as the heat and mass transfer coefficients are significantly affected by melting, thermophoresis and Brownian diffusion.

Chaves et al. (2015) have presented the numerical solutions for the problem of natural convection heat transfer by double diffusion from a heated cylinder buried in a saturated porous media exposed to constant uniform temperature and concentration in the cylinder and in the media surface. The Patankar's power law for approaching of variables calculated $T, C$, and $\phi$ also was adopted. In this work, a finite volume scheme has been used to predict the flow, temperature, and concentration distributions at any space from a heat cylinder buried into a fluid-saturated porous medium for a bipolar coordinates system. The authors found that the flow distribution is significantly affected by the Rayleigh number when the concentration distribution is considered.

The effects of chemical reaction and radiation on mixed convection heat and mass transfer over a vertical plate in power-law fluid saturated porous medium has been studied by Srinivasacharya and Swamy Reddy

${ }^{\dagger}$ Corresponding author. Email: driss_achemlal@yahoo.fr 
(2016). The results indicate that when the chemical reaction parameter increases, the velocity, concentration and heat transfer rate are reduced.

Thohura et al. (2016) have examined the phenomenon of natural convection flow of non-Newtonian fluid along a vertical thin cylinder with constant wall temperature using modified power law viscosity model. From the results, it can be concluded that, at the leading edge, a Newtonianlike solution exists as the shear rate is not large enough to trigger nonNewtonian effects.

Pullepu et al. (2016) have analyzed the free Convective flow from a vertical cone with mass transfer under the influence of chemical reaction and heat generation/absorption in the presence of UWT/UWC. This authors found that the thermal boundary layer becomes thick for higher values of, $S c, \Delta$ and lower values of $\operatorname{Pr}, \lambda$, and $N$ and the concentration boundary layer becomes thick for larger values of $\lambda$ and smaller values of $\operatorname{Pr}, S c, \Delta$ and $N$.

The effect of chemical reaction on free convection heat and mass transfer for a non-Newtonian power law fluid over a vertical flat plate embedded in a fluid-saturated porous medium has been studied, in the presence of the yield stress and the Soret effect, by Ibrahim et al. (2010). These authors show that the flow field is influenced appreciably by the presence of the chemical reaction parameter $\gamma$, the order of the chemical reaction parameter $m$, the Soret number $S r$, the buoyancy ratio $N$, the Lewis number $L e$, and the dimensionless rheological parameter $\Omega$.

Recently, El Haroui et al. (2017) have studied the thermosolutal free convection for Newtonian fluid in a saturated porous medium past a vertical porous plate exposed to three thermal states of the surface and constant concentration in the presence of chemical reaction, uniform suction or injection and Soret-Dufour effects. It was found that the chemical reaction has a relevent effect on the concentration field. Also, the fluid suction amplifies the wall heat transfer rate, but the fluid injection decreases it for the three thermal states of the plate. In addition, it was concluded that the heat transfer rate increases with the increase of the wall temperature index for all values of Soret number.

The majority of the previous studies are based on the constant physical parameters of the fluid. For most realistic fluids, the viscosity shows a rather pronounced variation with temperature. Thus it is necessary to take into account the variation of viscosity with temperature in order to accurately predict the heat and mass transfer rates.

The heat and mass transfer characteristics of natural convection about a vertical surface embedded in a saturated porous medium subject to variable viscosity are numerically analyzed by Moorthy and Senthilvadivu (2011). They have found that the thermal and species concentration boundary layer thickness increases for gases and decreases for liquids.

The effect of variable viscosity on free convection flow over a vertical flat plate embedded in a porous media saturated with non-Newtonian power law fluid in the presence of internal heat generation has been examined by Bagai and Nishad (2012) and Achemlal et al. (2014). Here, the effect of temperature dependent viscosity on heat transfer rates is investigated and it is shown that the heat transferred is more for a less viscous fluid.

This article extends our work Achemlal et al. (2014) and that of Moorthy and Senthilvadivu (2011) for dual-diffusion free convection along a vertical flat plate embedded in Darcy porous medium saturated with non-Newtonian fluids for three thermal states of the surface and a constant concentration. Numerical results of interest, such as the local Nusselt and Sherwood numbers, temperature, and concentration distributions, are presented at different values of the controlling parameters. It is hoped that the results obtained from the present investigation will provide useful information for application and also serve as a complement to the previous studies.

\section{PHYSICAL MODEL AND MATHEMATICAL ANALYSIS}

Our study is to investigate the double diffusive free convection induced by a heated vertical impermeable plate embedded in a saturated porous medium. The physical model is sketched in Fig. 1. The $x$-coordinate is measured along the plate and the $y$-coordinate normal to it. The plate is maintained at a variable temperature and a constant concentration, $T_{w}(x)$, and $C_{w}$, respectively. The temperature and concentration of the ambient medium are $T_{\infty}$ and $C_{\infty}$ respectively. The porous medium is considered homogeneous, isotropic and saturated with non-Newtonian and incompressible fluid with the presence of a chemical reaction. The flow is laminar, steady-state, and two-dimensional. Assume that the fluid and the porous medium have constant physical properties except for the density and viscosity variations. The fluid and the porous medium are supposed in local thermodynamical equilibrium. The Ostwaled-de Waele power-law model represents several non-Newtonian fluids of practical interest and therefore has been used in this study.

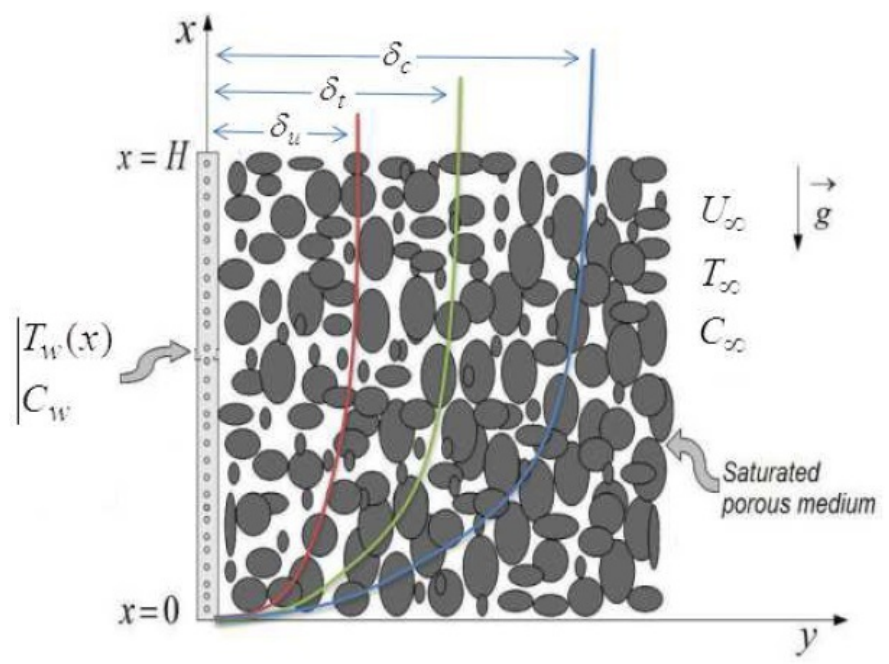

Fig. 1 Physical configuration and coordinate system. follows:

The governing equations describing the fluid flow can be written as

$$
\begin{gathered}
\frac{\partial u}{\partial x}+\frac{\partial v}{\partial y}=0 \\
U^{n-1} u=\frac{K(n)}{\mu}\left(\frac{\partial p}{\partial x}+\rho g\right), \\
U^{n-1} v=-\frac{K(n)}{\mu}\left(\frac{\partial p}{\partial y}\right) \\
u \frac{\partial T}{\partial x}+v \frac{\partial T}{\partial y}=\alpha\left(\frac{\partial^{2} T}{\partial x^{2}}+\frac{\partial^{2} T}{\partial y^{2}}\right), \\
u \frac{\partial C}{\partial x}+v \frac{\partial C}{\partial y}=D\left(\frac{\partial^{2} C}{\partial x^{2}}+\frac{\partial^{2} C}{\partial y^{2}}\right)-k_{1}\left(C-C_{\infty}\right)^{m} \\
\rho=\rho_{\infty}\left[1-\beta_{t}\left(T-T_{\infty}\right)-\beta_{c}\left(C-C_{\infty}\right)\right]
\end{gathered}
$$

where $U=\left|\sqrt{u^{2}+v^{2}}\right|$ is the velocity module

The appropriate boundary conditions of our problem are

$$
v=0, \quad T=T_{w}(x)=T_{\infty}+A x^{\lambda} \quad C=C_{w} \quad \text { at } \quad y=0,
$$

and

$$
u=U_{\infty}=0, \quad T=T_{\infty} \quad C=C_{\infty} \quad \text { as } \quad y \rightarrow \infty,
$$

where $u, v$ represent the velocity components along $x$ and $y$-axis, respectively, $n$ is the power-law viscosity index, $p$ is the pressure, $T$ is the fluid temperature, $C$ is the species concentration, $\alpha$ and $D$ are the effective thermal diffusivity and the mass diffusivity, respectively, $K$ is the permeability of the porous medium, $\beta_{t}$ is the thermal expansion coefficient, $\beta_{c}$ is the concentration expansion coefficient, $m$ is the reaction order, $k_{1}$ 
is the dimensional chemical reaction parameter, $\rho$ is the density, $g$ is the acceleration due to gravity and $\lambda$ is the power-law index of the wall temperature. In equation (2) and (3) $\mu$ denotes the viscosity of the fluid which is assumed to vary with temperature via the fluidity function $\varphi=\frac{\mu_{\infty}}{\mu}$;

$$
\varphi(T)=1+r\left(T-T_{\infty}\right)=r\left(T-T_{e}\right),
$$

where $-1 / r=T_{e}-T_{\infty}$ and $T_{e}$ and $r$ are constant and their values depend on the reference state of the fluid. In general, $r<0$ for gases and $r>0$ for liquids (see Lai and Kulacki (1990)). Also, $\theta_{r}$ is a constant which is defined by

$$
\theta_{r}=\frac{T_{e}-T_{\infty}}{T_{w}-T_{\infty}}=-\frac{1}{r\left(T_{w}-T_{\infty}\right)},
$$

It is worth mentioning here that for $r \rightarrow 0$ i.e. $\mu=\mu_{\infty}$ (constant) then $\theta_{r} \rightarrow \infty$. It is also important to note that $\theta_{r}$ is negative for liquids and positive for gases.

In equation (2) and (3) the permeability of the porous medium $K$ for flows of non-Newtonian power-law fluids is given by the following relationships provided by Christopher and Middleman (1965) and Dharmadhikari and Kale (1985), respectively :

$$
K=\left\{\begin{array}{l}
\frac{6}{25}\left[\frac{n \varepsilon}{3 n+1}\right]^{n}\left[\frac{d \varepsilon}{3(1-\varepsilon)}\right]^{n+1}, \\
\frac{2}{\varepsilon}\left[\frac{d \varepsilon^{2}}{8(1-\varepsilon)}\right]^{n+1}\left[\frac{6 n+1}{10 n-3}\right]\left[\frac{16}{75}\right]^{\frac{30 n-9}{10 n+11}},
\end{array}\right.
$$

where $d$ is the porous particle diameter while $\varepsilon$ is the porosity. $n$ is called the viscosity power-law index, that the case $n=1$ corresponds to a Newtonian fluid and the case $0<n<1$ is the power law relation proposed as being descriptive of pseudoplastic non-Newtonian fluids and $n>1$ describes the dilatant fluids.

All the studies on convection heat transfer in a porous medium show the thermal boundary layers exist adjacent to the heated or cooled surfaces Nield and Bejan (2017). When the thermal boundary layer is thin, the classical boundary layer approximations can be applied. The normal component of the velocity near the boundary is small compared with the other component of the velocity $(v<<u)$ and the derivatives of any quantity in the normal direction are large compared with derivatives of the quantity in direction of the plate. Invoking the boussinesq approximation, the pressure can be eliminated from Eqs. (2) and (3). By considering the assumptions mentioned above, the governing equations for this model are given by

$$
\begin{gathered}
\frac{\partial u}{\partial x}+\frac{\partial v}{\partial y}=0 \\
|u|^{n-1} u=\frac{\rho g \beta_{t} K(n)}{\mu}\left(T-T_{\infty}\right)+\frac{\rho g \beta_{c} K(n)}{\mu}\left(C-C_{\infty}\right) \\
u \frac{\partial T}{\partial x}+v \frac{\partial T}{\partial y}=\alpha \frac{\partial^{2} T}{\partial y^{2}} \\
u \frac{\partial C}{\partial x}+v \frac{\partial C}{\partial y}=D \frac{\partial^{2} C}{\partial y^{2}}-k_{1}\left(C-C_{\infty}\right)^{m}
\end{gathered}
$$

We introduce the following dimensionless similarity variable $\eta$ and the similarity functions $f(\eta), \theta(\eta)$ and $\phi(\eta)$ as

$$
\left\{\begin{array}{l}
\eta=\frac{y}{x} R a_{x}^{1 / 2}, \\
\psi=\alpha R a_{x}^{1 / 2} f(\eta), \\
\theta(\eta)=\frac{T-T_{\infty}}{T_{w}-T_{\infty}}, \\
\phi(\eta)=\frac{C-C_{\infty}}{C_{w}-C_{\infty}}, \\
R a_{x}=\left[\frac{\rho g \beta_{t} K(n)\left(T_{w}-T_{\infty}\right) x^{n}}{\mu_{\infty} \alpha^{n}}\right]^{1 / n}
\end{array}\right.
$$

where $\psi$ is the stream function defined by $u=\partial \psi / \partial y$ and $v=-\partial \psi / \partial x$, which identically satisfies the continuity Eq. (12), and $R a_{x}$ is the local Rayleigh number for the power-law fluids. In terms of these new variables, the momentum, energy and mass diffusion equations together with the boundary conditions become,

$$
\begin{gathered}
\left(f^{\prime}\right)^{n}+(\theta+N \phi)\left(\frac{\theta-\theta_{r}}{\theta_{r}}\right)=0 \\
\theta^{\prime \prime}+\frac{1}{2}\left(\frac{\lambda+n}{n}\right) f \theta^{\prime}-\lambda \theta f^{\prime}=0 \\
\frac{1}{L e} \phi^{\prime \prime}+\frac{1}{2}\left(\frac{\lambda+n}{n}\right) f \phi^{\prime}-\delta \phi^{m}=0
\end{gathered}
$$

and

$$
\begin{aligned}
& f=0, \quad \theta=1 \quad \phi=1 \quad \text { at } \quad \eta=0, \\
& f^{\prime}=0, \quad \theta=0 \quad \phi=0 \quad \text { as } \quad \eta \rightarrow \infty,
\end{aligned}
$$

where the primes in Eqs.(17)-(19) denote differentiation with respect to the similarity variable $\eta$. Here the parameters $N, L e$ and $\delta$ are the sustentation parameter, the Lewis parameter and the reaction rate parameter respectively. They are defined by

$$
\begin{aligned}
& N=\frac{\beta_{c}\left(C_{w}-C_{\infty}\right)}{\beta_{t}\left(T_{w}-T_{\infty}\right)}, \\
& L e=\frac{\alpha}{D}, \\
& \delta=\frac{k_{1}\left(C_{w}-C_{\infty}\right)^{m-1} x^{2}}{\alpha R a_{x}}
\end{aligned}
$$

The parameter $\delta$ in the species diffusion Eq.(19) represents the following three situations : $\delta>0$, for destructive chemical reaction; $\delta<0$, for generative chemical reaction ; and $\delta=0$, for no reaction. This study is focused on three different cases : the first case $(\lambda=0)$ corresponds to isothermal surface ; the second case $(\lambda=1)$ represents linear temperature along the vertical surface ; and the third case $(\lambda=1 / 2)$ represents square root temperature variation along the surface.

For practical applications, it is usually the velocity components are of interest. These are given by

$$
\begin{aligned}
& u=\frac{\alpha}{x} R a_{x} f^{\prime}(\eta) \\
& v=-\frac{\alpha R a_{x}^{1 / 2}}{2 x}\left[\frac{(\lambda-n)}{n} \eta f^{\prime}(\eta)+\frac{(\lambda+n)}{n} f(\eta)\right]
\end{aligned}
$$

The parameters of the engineering interest for the present problem are the local Nusselt number and the Sherwood number, which are given by the following expressions :

$$
\begin{aligned}
& \frac{N u_{x}}{R a_{x}^{1 / 2}}=-\theta^{\prime}(0), \\
& \frac{S h_{x}}{R a_{x}^{1 / 2}}=-\phi^{\prime}(0)
\end{aligned}
$$

\section{NUMERICAL METHOD AND VALIDATION}

The set of coupled nonlinear ordinary differential Eqs. (17)-(19), subject to the boundary conditions (20), are solved numerically for three thermal states of the surface mentioned earlier by using the fifth order RungeKutta scheme accompanied by the soothing method. The numerical computations are carried out by a program which uses a computational computer language Fortran on a Core i7 PC machine. At specified values of $\lambda$ and $n$, the values of $\theta^{\prime}(0)$ and $\phi^{\prime}(0)$ are predicted and Eqs.(17)-(19) are integrated until the boundary conditions at infinity $f^{\prime}(\eta), \theta(\eta)$ and $\phi(\eta)$ decay exponentially to zero. If the boundary conditions at infinity are not satisfied then the numerical routine uses the calculated corrections to the estimated values of $\theta^{\prime}(0)$ and $\phi^{\prime}(0)$. This process, which known as shoo- 
Table 1 Comparison of $-\theta^{\prime}(0)$ and $-\phi^{\prime}(0)$ to previously published data at $n=1$ and $\theta_{r} \rightarrow-\infty$ for different values of $L e$ number.

\begin{tabular}{|c|c|c|c|c|c|c|c|c|}
\hline \multirow[b]{2}{*}{$L e$} & \multirow[b]{2}{*}{$\lambda$} & \multirow[b]{2}{*}{$N$} & \multicolumn{3}{|c|}{$-\theta^{\prime}(0)$} & \multicolumn{3}{|c|}{$-\phi^{\prime}(0)$} \\
\hline & & & Current Results & El-Arabawy & $\mathrm{RE}\left(\times 10^{-6}\right)$ & Current Results & El-Arabawy & $\operatorname{RE}\left(\times 10^{-6}\right)$ \\
\hline 1 & $-1 / 4$ & 1 & 0.219591 & 0.219543 & 218.64 & 0.563437 & 0.563420 & 30.17 \\
\hline 2 & & & 0.204954 & 0.204821 & 649.35 & 0.829150 & 0.829150 & 0.00 \\
\hline 4 & & & 0.192265 & 0.192031 & 1218.55 & 1.202416 & 1.202460 & 36.59 \\
\hline 6 & & & 0.186287 & 0.186000 & 1543.01 & 1.486871 & 1.486920 & 32.95 \\
\hline 8 & & & 0.182706 & 0.182385 & 1760.01 & 1.725809 & 1.725870 & 35.34 \\
\hline 10 & & & 0.180278 & 0.179935 & 1906.24 & 1.935864 & 1.935930 & 34.09 \\
\hline 1 & 0 & 1 & 0.627561 & 0.627556 & 7.97 & 0.627561 & 0.627556 & 7.97 \\
\hline 2 & & & 0.592630 & 0.592601 & 48.94 & 0.929541 & 0.929544 & 3.23 \\
\hline 4 & & & 0.558560 & 0.558504 & 100.27 & 1.357454 & 1.357470 & 11.79 \\
\hline 6 & & & 0.540844 & 0.540770 & 136.84 & 1.684696 & 1.684710 & 8.31 \\
\hline 8 & & & 0.529530 & 0.529445 & 160.55 & 1.959934 & 1.959950 & 8.16 \\
\hline 10 & & & 0.521493 & 0.521401 & 176.45 & 2.202059 & 2.202080 & 9.54 \\
\hline 1 & $1 / 4$ & 1 & 0.899680 & 0.899681 & 1.11 & 0.690199 & 0.690194 & 7.24 \\
\hline 2 & & & 0.854021 & 0.854011 & 11.71 & 1.024962 & 1.024960 & 1.95 \\
\hline 4 & & & 0.807172 & 0.807143 & 35.93 & 1.501479 & 1.501490 & 7.33 \\
\hline 6 & & & 0.781797 & 0.781763 & 43.49 & 1.866622 & 1.866630 & 4.29 \\
\hline 8 & & & 0.765184 & 0.761763 & 4490.90 & 2.173967 & 2.173980 & 5.98 \\
\hline 10 & & & 0.753198 & 0.753159 & 51.78 & 2.444436 & 2.444450 & 5.73 \\
\hline
\end{tabular}

ting method, is repeated iteratively until the boundary conditions at infinity are satisfied for $f^{\prime}(\eta), \theta(\eta)$ and $\phi(\eta)$. A uniform step size of $\Delta \eta=0.001$ is found to be satisfactory to give results that converge to within an error of $10^{-6}$ in nearly all the cases. The value of $\eta_{\infty}$ was chosen as large as possible, without causing numerical instability in the resulted $f^{\prime}, \theta$ and $\phi$.

For checking our method, we have compared the obtained results with the available published data in Table 1 in terms of $-\theta^{\prime}(0)$ and $-\phi^{\prime}(0)$ in the case of Newtonian fluid flow $(\mathrm{n}=1)$ for selected values of the the temperature exponent $\lambda$ and $L_{e}$ number at $N=1$ and $\theta_{r} \rightarrow \infty$. It is clear from this table, that the maximum relative error from El-Arabawy (2009) results are less than $0.45 \%$ for the three cases of the plate surface. We can said here that the comparisons in all the above cases are found to be in excellent agreement. This favorable comparison lends confidence in the numerical results to be reported in the next section.

\section{RESULTS ANALYSIS}

In this section, a representative set of graphical results is presented in Figures 2 - 19 at $L e=1$ and $N=1$. These figures illustrate the influence of the viscosity parameter $\theta_{r}$, the temperature exponent $\lambda$, the power law index $n$, the chemical reaction parameter $\delta$ and the order of the chemical reaction parameter $m$ on the temperature, concentration, Nusselt number and Sherwood number profiles.

\subsection{Temperature field}

The figures 2 and 3 show respectivelly for $n=0.5$ and $n=2$, the effect of the viscosity parameter $\left(\theta_{r}<0\right)$ on dimensionnless thermal profiles in the boundary layer area of an isothermal and impermeable vertical plate embedded in a saturated porous medium in the presence of a first order chemical reaction. It is clearly remarkable that the temperature decreases when $\theta_{r} \rightarrow 0$ and this decrease is greater for pseudoplastic fluids than for dilatant fluids. It can be concluded here, that the less viscous fluids promote more the heat transfer in the boundary layer area and therefore enlarge the thermal boundary layer thickness. For the dilatant fluids, it is clearly understood that the variable viscosity has less influence on the temperature distributions.

In figures 4 and 5 , the isothermal lines close an isothermal and impermeable vertical plate $\left(T_{w}=353.15 \mathrm{~K}, T_{\infty}=293.15 \mathrm{~K}\right)$ in a porous medium saturated by a pseudoplastic fluid ( $n=0.5$, oil at $T_{f}=323.15 \mathrm{~K}$ ) in the presence of the first order destructive chemical reaction for $\theta_{r}=-100$ and $\theta_{r}=-1$ are presented, respectively. We can say here that, in the boundary layer area, the heat exchange by convection from the plate to the porous medium is faster when the fluid is less viscous (Fig. 5). This can be explained physically by the fact that the less viscous fluids can flow more easily compared to the case of the more viscous fluids which allows to transmit more heat to the porous medium.

Figures 6,7 and 8 show respectively, for three thermal states of the plate $\lambda=0, \lambda=1 / 2$ and $\lambda=1$, the isothermal lines around a heated vertical plate placed in a porous medium saturated by a pseudplastique fluid ( $n=0.5$, oil at $T_{f}=323.15 \mathrm{~K}$ and $\theta_{r}=-20$ ). From these figures, it is notable that the fluid activity at upper portion of the plate increases with increased $\lambda$ due to more amount of heat in that portion of the plate. The thinning of the thermal boundary layer is evident for increasing the surface temperature exponent from a uniform to a linear form and it can be also observed that all the heat was transferred from the surface to the porous medium.

The effect of the rheological behavior of the fluid on the isothermal lines in the boundary layer area of an isothermal and impermeable plate $\left(T_{w}=353.15 \mathrm{~K}, T_{\infty}=293.15 \mathrm{~K}\right)$ introduced vertically in a porous 


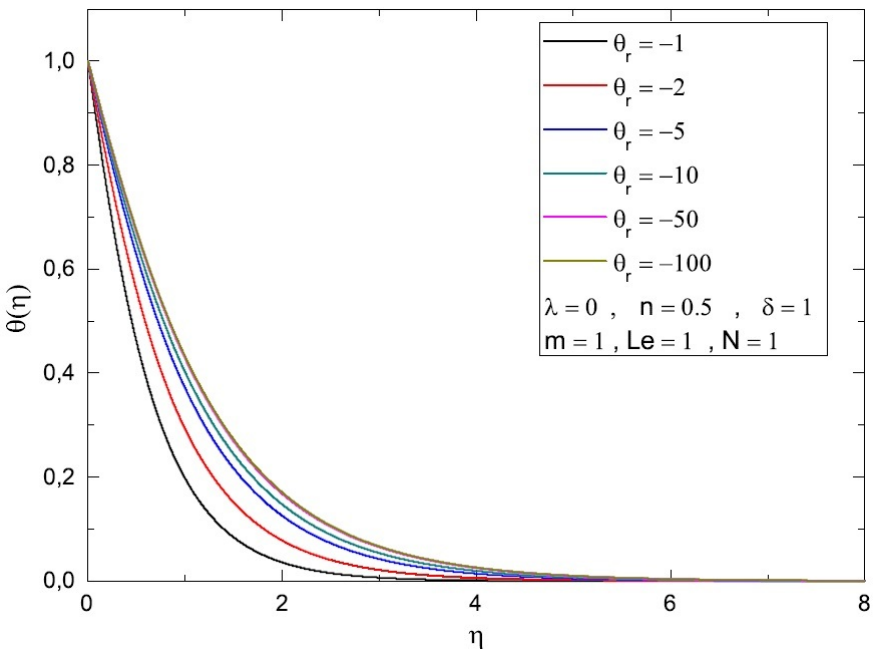

Fig. $2 \theta(\eta)$ profiles for $\lambda=0, n=0.5$ and various values of $\theta_{r}<0$.

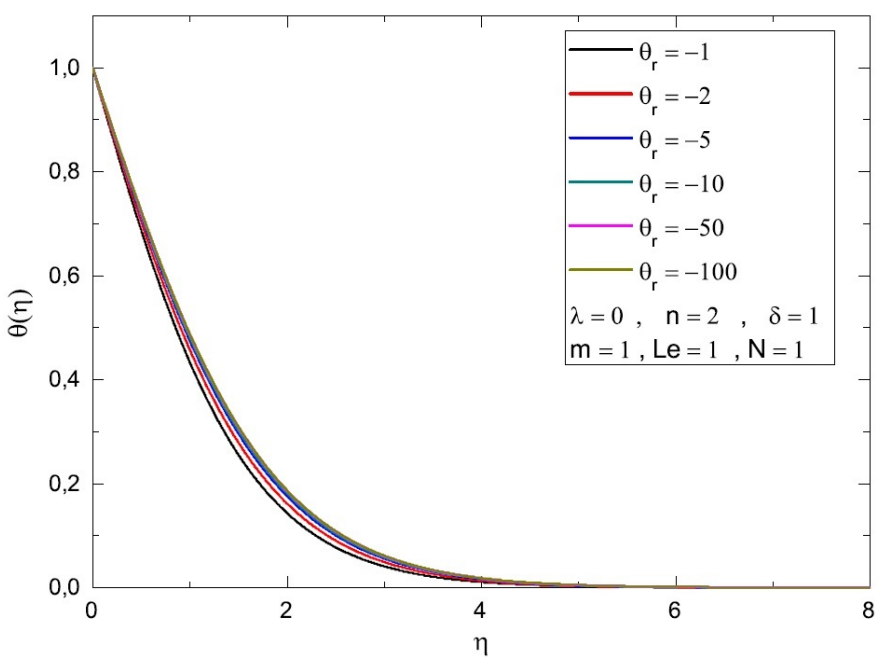

Fig. $3 \theta(\eta)$ profiles for $\lambda=0, n=2$ and various values of $\theta_{r}<0$.

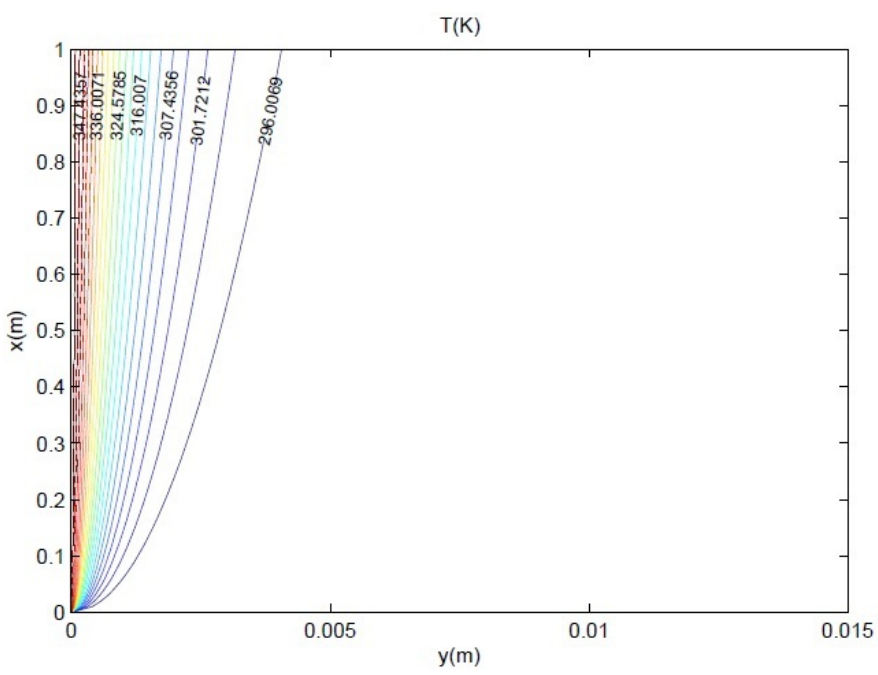

Fig. 4 Isothermal lines according to $x$ and $y$ at $\lambda=0$ for $n=0.5, \delta=1$, $m=1$ and $\theta_{r}=-1$.

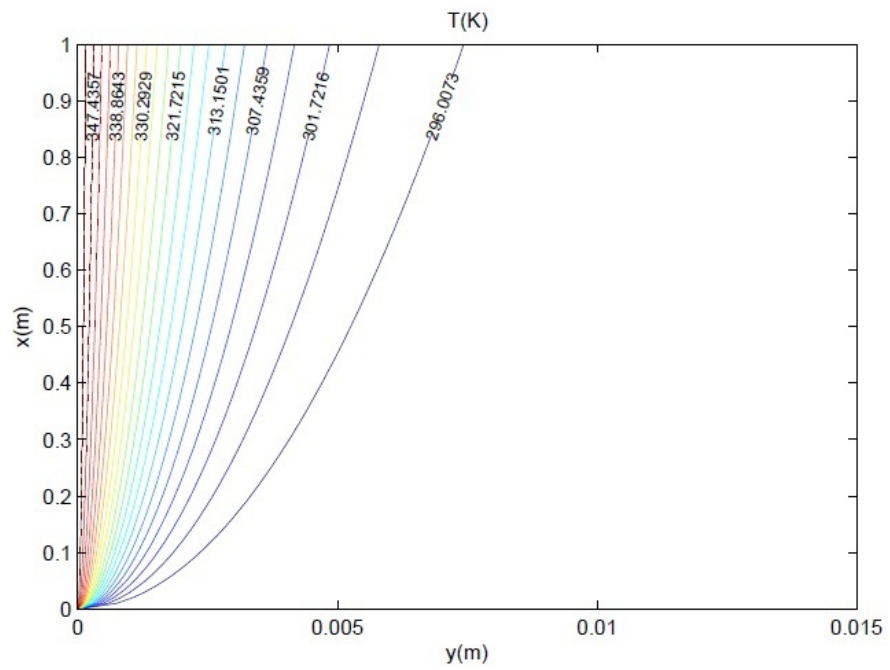

Fig. 5 Isothermal lines according to $x$ and $y$ at $\lambda=0$ for $n=0.5, \delta=1$, $m=1$ and $\theta_{r}=-100$.

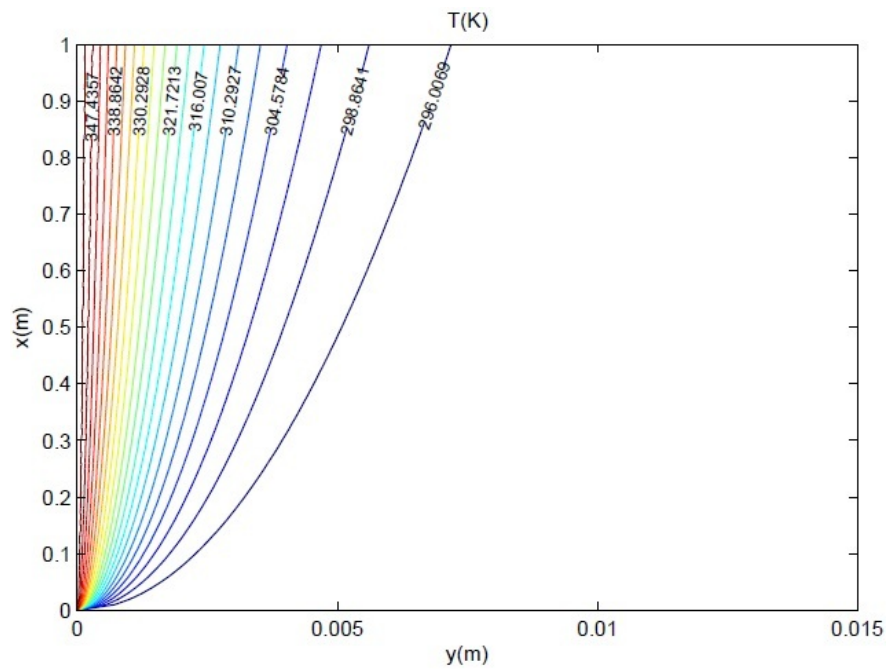

Fig. 6 Isothermal lines according to $x$ and $y$ at $\lambda=0$ for $n=0.5, \delta=1$, $m=1$ and $\theta_{r}=-20$.

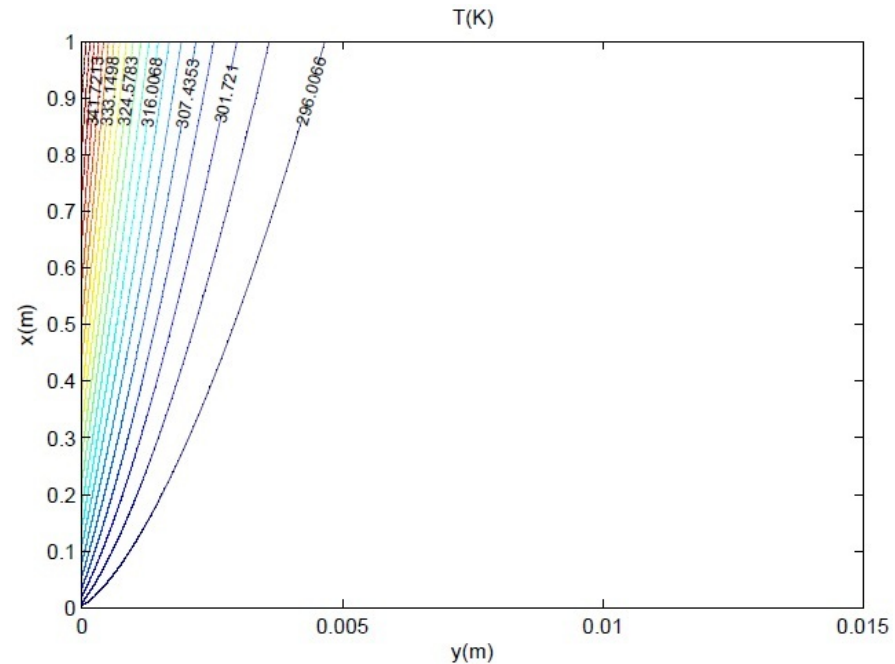

Fig. 7 Isothermal lines according to $x$ and $y$ at $\lambda=1 / 2$ for $n=0.5$, $\delta=1, m=1$ and $\theta_{r}=-20$. 


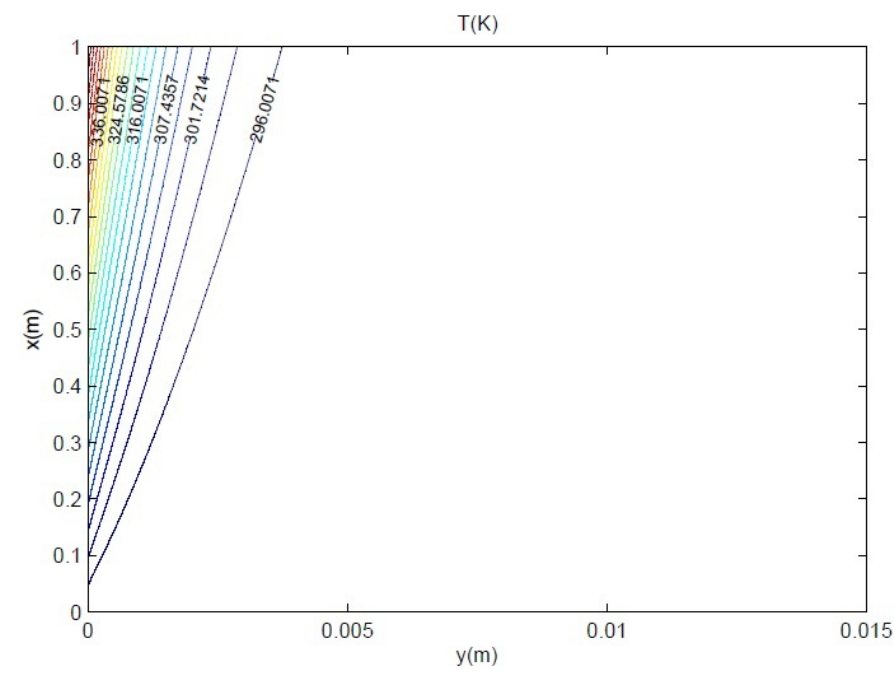

Fig. 8 Isothermal lines according to $x$ and $y$ at $\lambda=1$ for $n=0.5, \delta=1$, $m=1$ and $\theta_{r}=-20$.

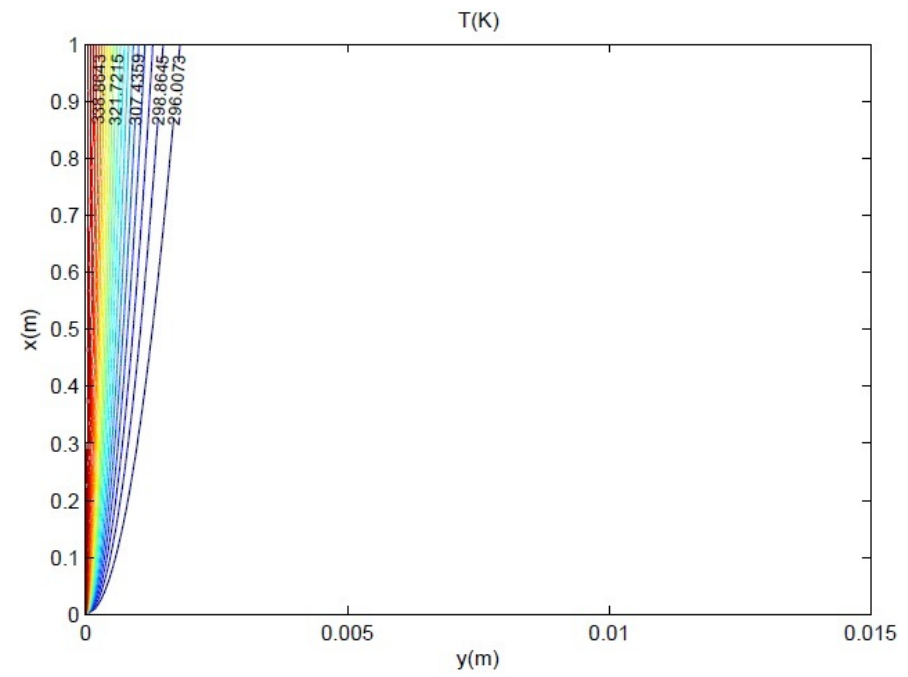

Fig. 9 Isothermal lines according to $x$ and $y$ at $\lambda=0$ for $\delta=1, m=1$, $\theta_{r}=-20$ and $n=3$.

medium saturated by a pseudoplastic fluid $\left(n=0.5\right.$ at $\theta_{r}=-20$ ) in the presence of a first order destructive chemical reaction is shown in figures 6 (oil case) and 9 (honey case). We conclude from these figures that the porous medium saturated by a pseudoplastic fluid transmits more heat from the wall to the porous medium compared to the porous medium saturated by a dilatant fluid. This transmission characteristics is suitable for use more it in the industriales applications.

\subsection{Mass concentration}

Figure 10 shows the effect of the presence of a first order chemical reaction in the medium on dimensionless concentration profiles in the boundary layer area of an isothermal and impermeable plate embedded in a saturated porous medium by a pseudoplastic fluid ( $n=0.5$ at $\left.\theta_{r}=-20\right)$. From this figure, it clearly notable that the presence of a generative chemical reaction helps to promote the solute transfer in the boundary layer area and consequently expands the concentration boundary layer thickness unlike the presence of a destructive chemical reaction where the concentration boundary layer is reduced.

The effect of the exponent of the fluid $n$ on the isoconcentration lines in the boundary layer area of an isothermal and impermeable plate $\left(C_{w}=\right.$
$40 \mathrm{~g} / \mathrm{l}, C_{\infty}=2 \mathrm{~g} / \mathrm{l}$ ) placed vertically in a porous medium saturated by a pseudoplastic fluid ( $n=0.5$ at $\left.\theta_{r}=-20\right)$ in the presence of a first order destructive chemical reaction is shown in figures 11 and 12. It is concluded from these figures that the pseudoplastic fluids promote more the solute transfer from the wall to the porous medium and therefore lead to the expansion of the concentration boundary layer thickness. On the contrary, the dilatant fluids show an opposite behavior to a pseudoplastic fluids. This behavior is already shown in figures 6 and 9 for the case of heat transfer.

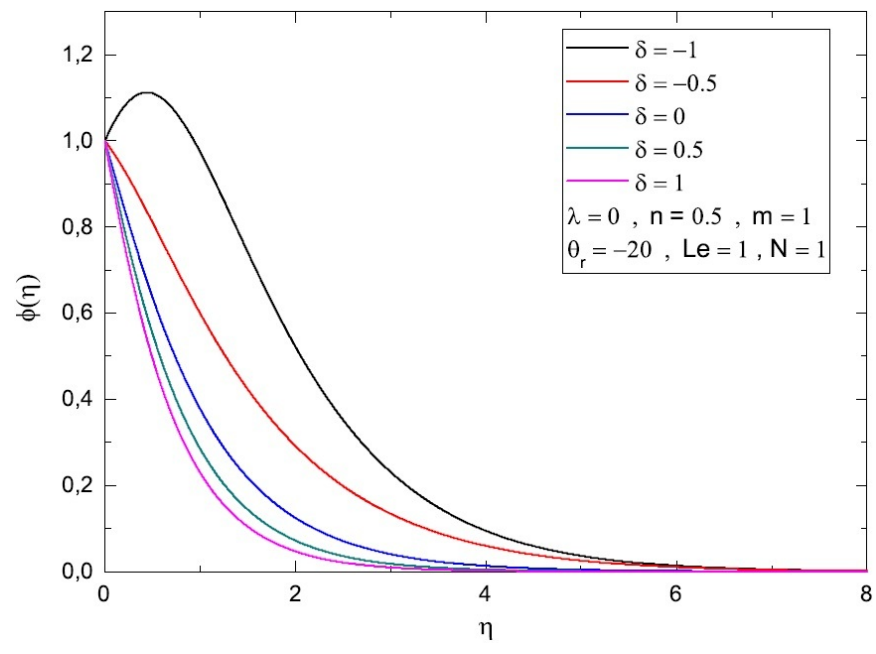

Fig. $10 \phi(\eta)$ profiles for $\lambda=0, n=0.5$ and various values of $\delta$.

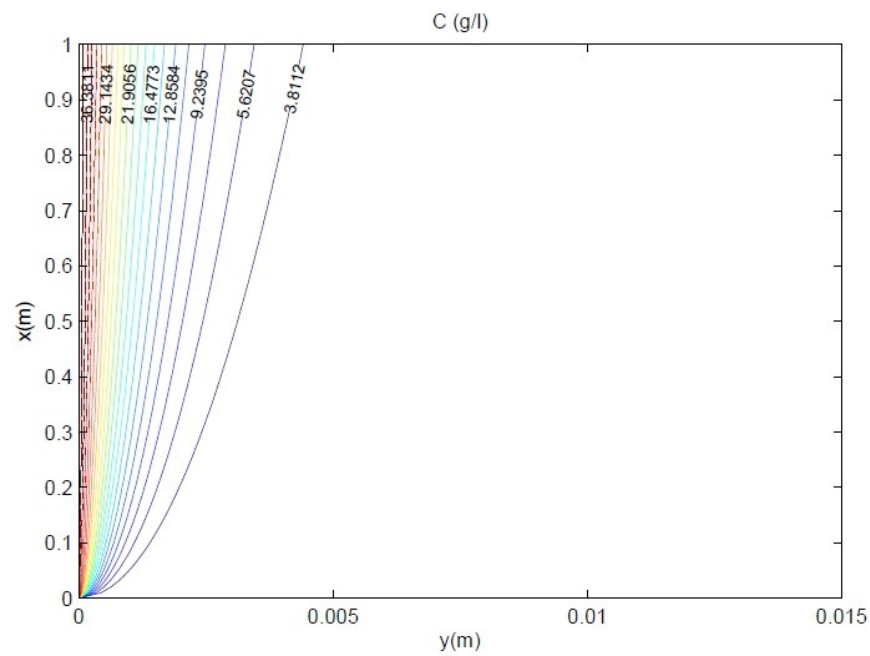

Fig. 11 Isoconcentration lines according to $x$ and $y$ at $\lambda=0$ for $\delta=1$, $m=1, \theta_{r}=-20$ and $n=0.5$.

The effect of the presence of a first order generative or destructive chemical reaction on the isoconcentration lines in the boundary layer area of an isothermal and impermeable plate $\left(C_{w}=40 \mathrm{~g} / \mathrm{l}, C_{\infty}=\right.$ $2 \mathrm{~g} / \mathrm{l}$ ) buried into a pseudoplastic fluid saturated porous medium $(n=$ 0.5 at $\theta_{r}=-20$ ) is presented in figures 13 and 14 . These figures confirm that the generative chemical reaction favorites more the solute transfer in the medium unlink the case of destructive chemical reaction where the concentration boundary layer becomes thicker.

The influence of the chemical reaction order on the species transfer in the boundary layer area of an isothermal and impermeable vertical plate $\left(C_{w}=40 \mathrm{~g} / \mathrm{l}, C_{\infty}=2 \mathrm{~g} / \mathrm{l}\right)$ posed into a pseudoplastic fluid saturated porous medium ( $n=0.5$ at $\left.\theta_{r}=-20\right)$ is illustrated in the figures 13 and 15 for the case of a generative chemical reaction and in the figures 


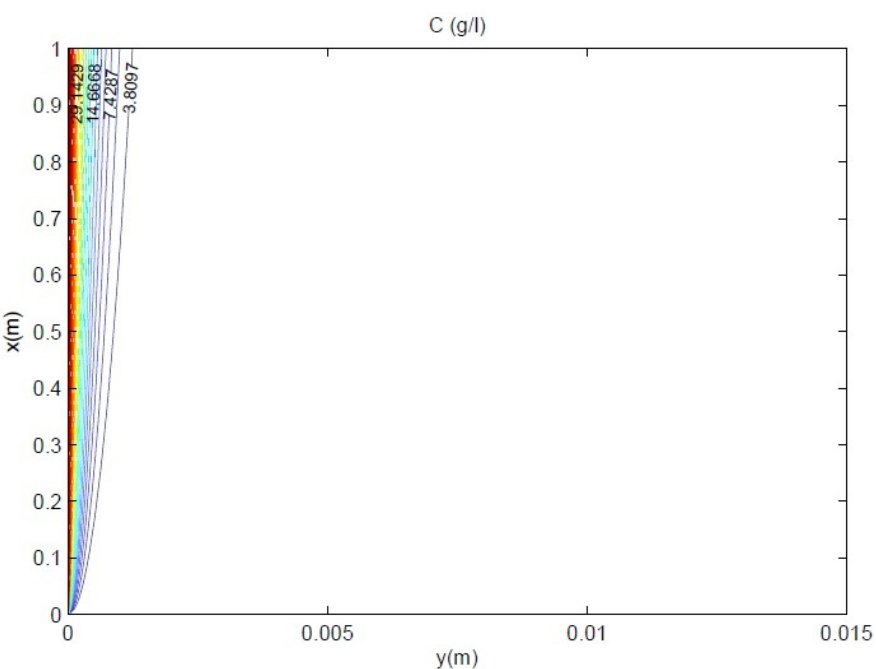

Fig. 12 Isoconcentration lines according to $x$ and $y$ at $\lambda=0$ for $\delta=1$, $m=1, \theta_{r}=-20$ and $n=3$.

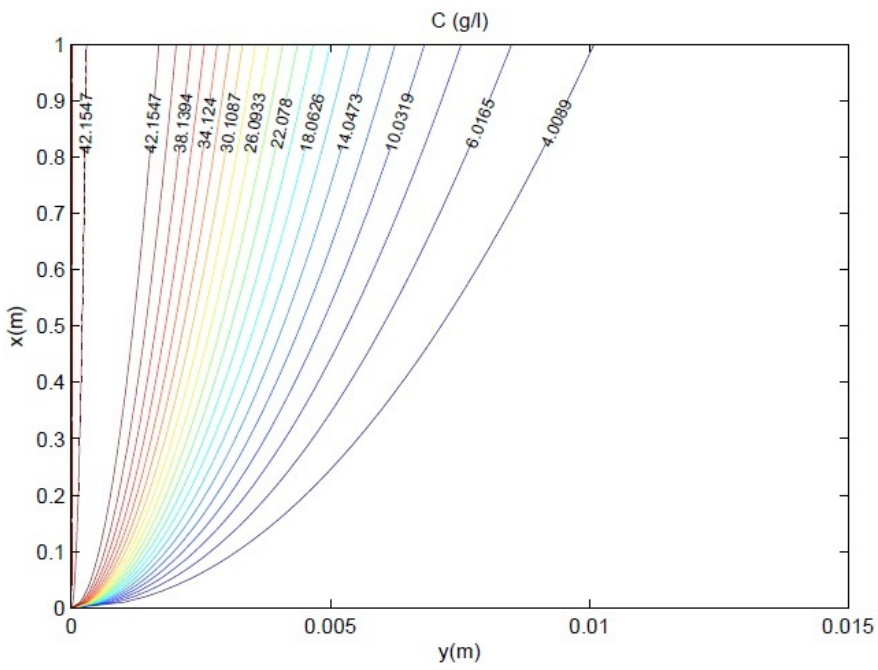

Fig. 13 Isoconcentration lines according to $x$ and $y$ at $\lambda=0$ for $n=0.5$, $\delta=-1$ and $m=1$.

14 and 16 for the case of a destructive chemical reaction. From these figures it is clearly remarkable that the increase of a chemical reaction order disfavoring the species transfer from the plate to the porous medium and therefore stabilized the concentration boundary layer thickness in the case of a generative chemical reaction unlike the case of a destructive chemical reaction.

\subsection{Local Nusselt number}

Figure 17 illustrates the heat transfer rate at the wall according to the viscosity parameter $\theta_{r}$ for an isothermal and impermeable plate vertically placed into a porous medium saturated by three type of fluids $(n=0.5,1$ and 2) in the presence of a first order destructive chemical reaction. From this figure it is clearly remarkable that the rate of heat transfer at the surface is more important in the case of pseudoplastic fluid than in the case of dilatant fluid regardless of fluid viscosity. Furthermore, it is obvious that in the case of liquids $\left(\theta_{r}<0\right)$ the heat transfer rate is more than that for the constant viscosity case. The opposite behavior has been observed in the case of gases $\left(\theta_{r}>0\right)$. The similar trend for the case of flow over a vertical plate has been also found by Lai and Kulacki (1990).

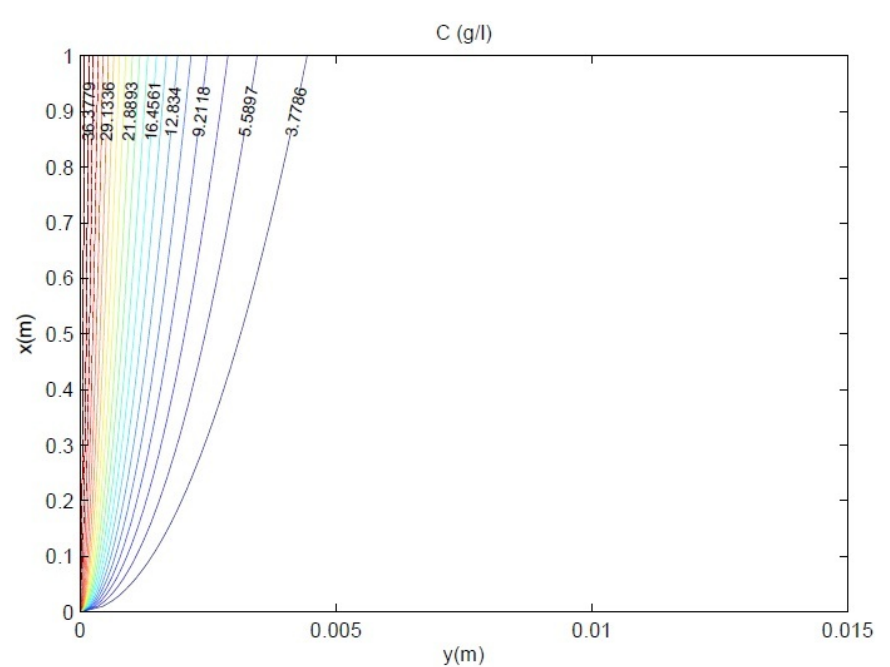

Fig. 14 Isoconcentration lines according to $x$ and $y$ at $\lambda=0$ for $n=0.5$, $\delta=1$ and $m=1$

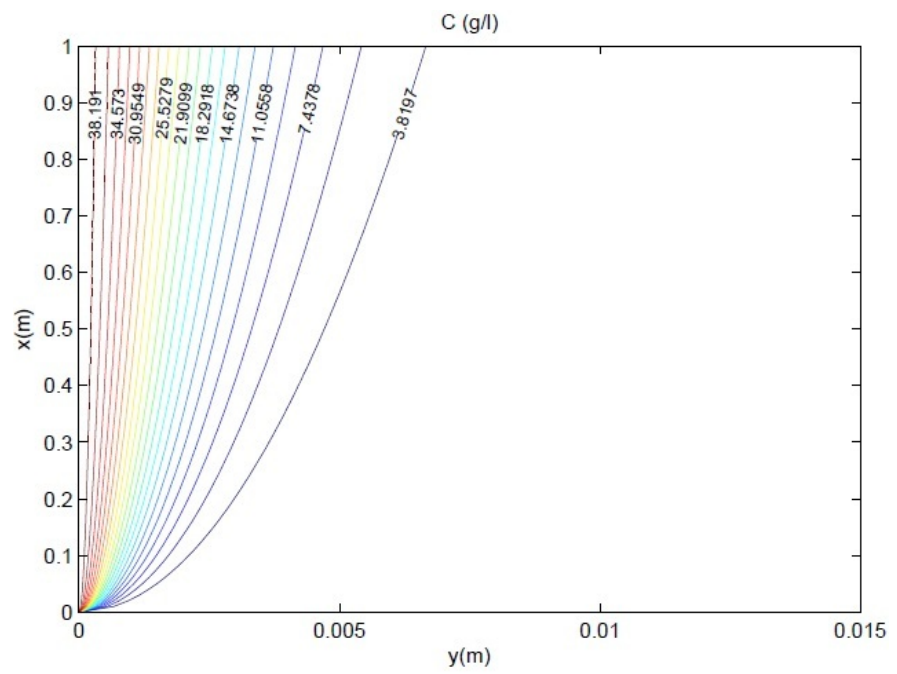

Fig. 15 Isoconcentration lines according to $x$ and $y$ at $\lambda=0$ for $n=0.5$, $\delta=-1$ and $m=2$.

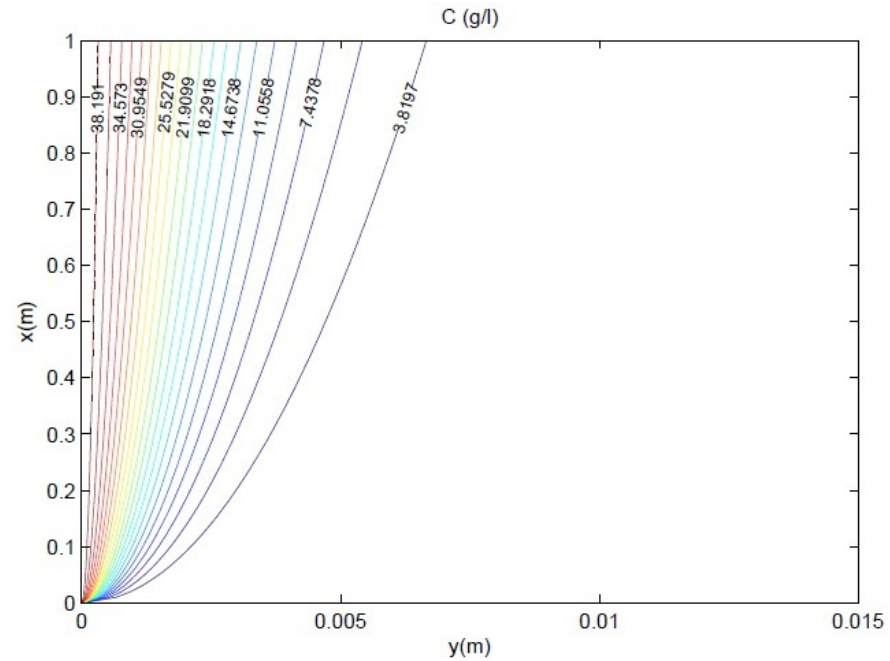

Fig. 16 Isoconcentration lines according to $x$ and $y$ at $\lambda=0$ for $n=0.5$, $\delta=1$ and $m=2$. 


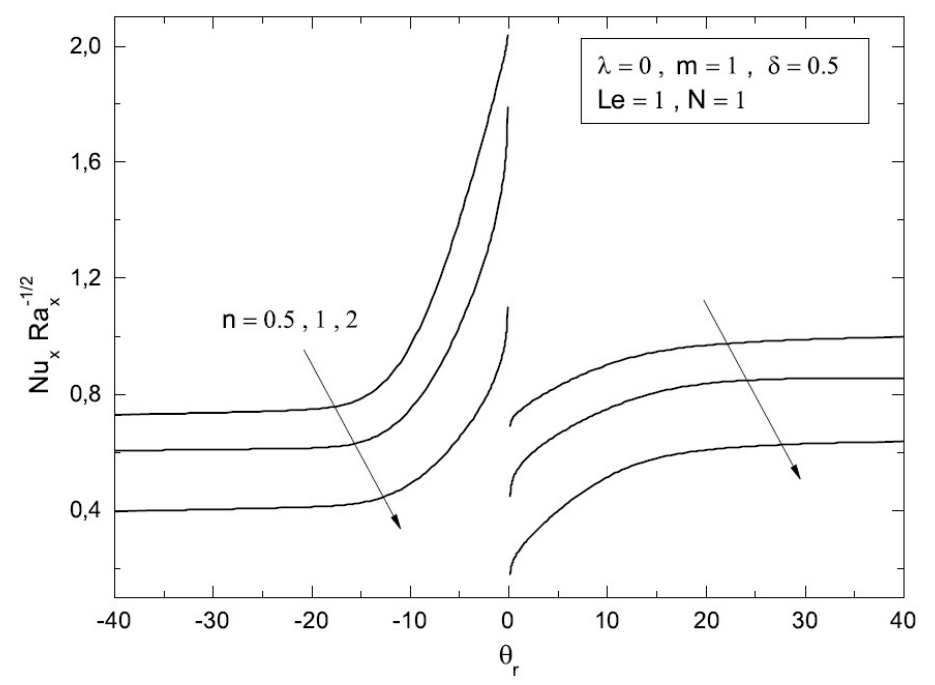

Fig. $17 N u_{x}$ distributions versus $\theta_{r}$ for $\lambda=0, \delta=0.5, m=1$ and various values of $n$.

\subsection{Local Sherwood number}

Figure 18 shows the species transfer rate at the wall, for an isothermal and impermeable plate buried into a pseudoplastic fluid saturated porous medium ( $n=0.5$ at $\theta_{r}=-20$ ), according to the chemical reaction parameter $\delta$ for three values of the chemical reaction order $(m=1,2$ and $3)$. Here, it is observed that the species transfer rate increases with increasing chemical reaction parameter $\delta$ for all values of the parameter $m$ considered. Also, it is important to note that this transfer rate increases with increasing $m$ in the presence of a generative chemical reaction and decreases in the case of a destructive chemical reaction.

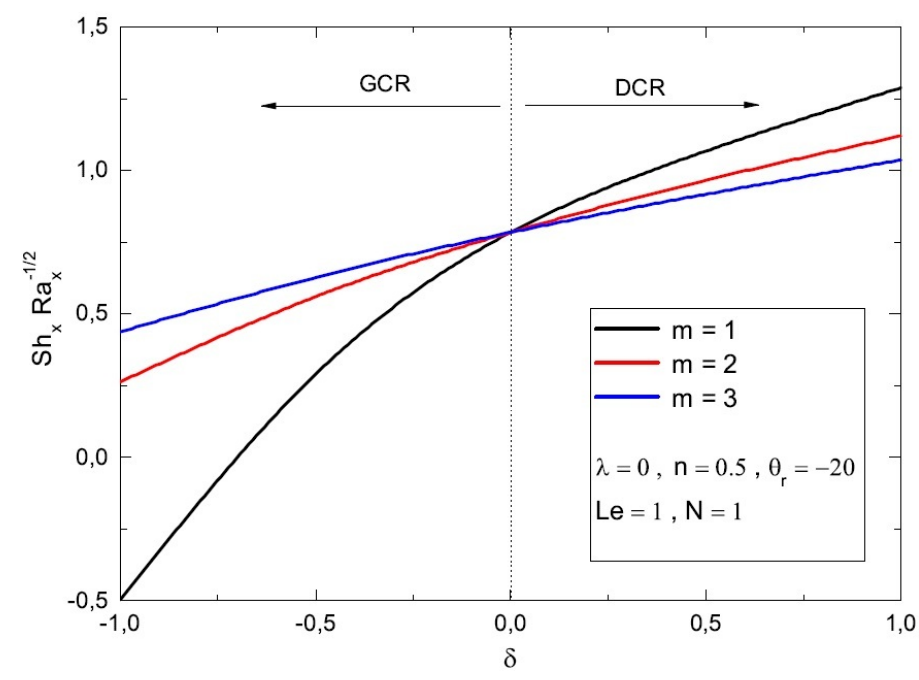

Fig. $18 S h_{x}$ distributions versus $\delta$ for $\lambda=0, n=0.5$ and selected values of $m$.

Figure 19 describes the mass transfer rate at the surface of an isothermal and impermeable plate, embedded into a pseudoplastic fluid saturated porous medium $(n=0.5)$, according to the parameter $n$ for selected values of the viscosity parameter $\theta_{r}\left(\theta_{r}<0\right)$ in the presence of a first order destructive chemical reaction $(\delta=0.5)$. One can easily conclude that the mass transfer rate at the wall is very important when $\theta_{r} \rightarrow 0\left(\theta_{r}<0\right)$ for pseudoplastic fluids $(n<1)$ but no significant influence of the viscosity parameter on the mass transfer rate is shown for dilatant fluids. For all values of $\theta_{r}$ considered, the local Sherwood number near the leading edge decays sharply as the value of the parameter $n$ moves from the range of the pseudoplastic fluids to the range of the dilatant fluids.

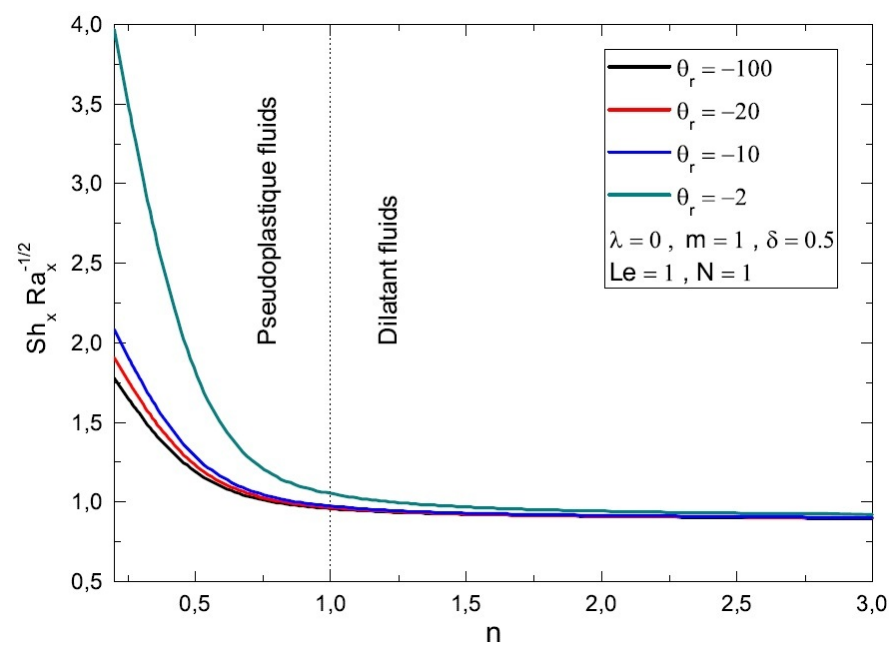

Fig. $19 S h_{x}$ distributions versus $n$ for $\lambda=0, \delta=0.5$ and various values of $\theta_{r}$.

\section{CONCLUSION}

Steady natural convection heat transfer by double diffusion from a heated vertical plate buried in a non-Newtonian fluid saturated porous medium is studied numerically. The fifth order Runge-Kutta scheme together with the shooting method has been used to predict the flow, temperature, and concentration distributions at any space from a heated plate. This study has been accompanied by the graphic representations and detailed analyses at the physical character. The following conclusions can be drawn as a result of the computations:

- A comparison with published work on a special case of the problem was realized and the results were found to be in good agreement.

- The effect of a variable viscosity on the temperature distribution is significant for pseudoplastic fluids than for dilatant fluids.

- The thinning of the thermal boundary layer is evident for increasing the surface temperature exponent and the viscosity parameter $\theta_{r}$ $\left(\theta_{r}<0\right)$.

- The generative first order chemical reaction effect $(\delta<0)$ causes thicker concentration boundary layer while the destructive first order chemical reaction effect $(\delta>0)$ has the tendency to reduce the thickness of concentration boundary layer.

- The increases of the order of the chemical reaction parameter $m$ causes a thicker concentration boundary layer in the case of a destructive chemical reaction and a thinner concentration boundary layer in the case of a generative chemical reaction.

- The heat transfer rate is more in the case of liquids when the variable viscosity is considered as compared to the constant viscosity case. In the case of gases, it is less than the constant viscosity case.

- The rate of heat and mass transfer are more important in the case of pseudoplastic fluids than in the case of dilatant fluids as $\theta_{r} \rightarrow 0$ for liquids $\left(\theta_{r}<0\right)$.

- The species transfer rate increases with increasing chemical reaction parameter $\delta$. Also, this rate is amplified with increasing $m$ in the presence of a generative chemical reaction and reduced in the case of a destructive chemical reaction. 


\section{NOMENCLATURE}

$A \quad$ wall temperature parameter.

$C \quad$ fluid concentration $\left(K g \cdot \mathrm{m}^{-3}\right)$.

$D \quad$ mass diffusivity $\left(m^{2} \cdot s^{-1}\right)$.

$D C R$ destructive chemical reaction.

$f \quad$ dimensionless stream function.

$G C R$ generative chemical reaction.

$g \quad$ gravitational acceleration $\left(m . s^{-2}\right)$.

$H$ the plate length $(m)$.

$K$ permeability of the porous medium $\left(\mathrm{m}^{2}\right)$.

$k_{1} \quad$ dimensional chemical reaction parameter.

Le Lewis number.

$m$ chemical reaction order.

$N \quad$ sustentation parameter.

$N u_{x} \quad$ local Nusselt number.

$n \quad$ power-law viscosity index.

$p \quad$ pressure $(P a)$.

$R a_{x} \quad$ local Rayleigh number.

$R E$ relative error.

$S h_{x} \quad$ local Sherwood number.

$T \quad$ fluid temperature $(K)$.

$u \quad$ velocity component in $\mathrm{x}$ direction $\left(m . s^{-1}\right)$.

$v \quad$ velocity component in y direction $\left(m . s^{-1}\right)$.

$x \quad$ coordinate along the plate $(m)$.

$y \quad$ coordinate normal to the plate $(m)$. derivative with respect to $\eta$.

\section{Greek symbols}

$\alpha \quad$ equivalent thermal diffusivity $\left(m^{2} \cdot s^{-1}\right)$.

$\beta_{c} \quad$ concentration expansion coefficient $\left(K g^{-1} \cdot m^{-3}\right)$.

$\beta_{t} \quad$ thermal expansion coefficient $\left(K^{-1}\right)$.

$\delta \quad$ dimensionless reaction parameter.

$\delta_{c} \quad$ concentration boundary layer thickness $(m)$.

$\delta_{d} \quad$ dynamic boundary layer thickness $(m)$.

$\delta_{t} \quad$ thermal boundary layer thickness $(m)$.

$\varepsilon \quad$ porosity.

$\eta \quad$ similarity variable.

$\theta \quad$ dimensionless temperature.

$\theta_{r} \quad$ viscosity parameter.

$\lambda \quad$ temperature exponent.

$\mu \quad$ dynamic viscosity $\left(K g \cdot m^{-1} \cdot s^{-1}\right)$.

$\nu \quad$ kinematic viscosity $\left(m^{2} \cdot s^{-1}\right)$.

$\rho \quad$ fluid density $\left(K g \cdot \mathrm{m}^{-3}\right)$.

$\phi \quad$ dimensionless concentration.

$\psi \quad$ stream function.

\section{Subscripts}

$w \quad$ wall plate condition.

$\infty \quad$ infinity plate condition.

\section{REFERENCES}

Achemlal, D., Sriti, M., and El Haroui, M., 2014, "Viscosity and Fluid Suction/Injection Effects on Free Convection Flow from a Vertical Plate in a Porous Medium Saturated with a Pseudoplastic Fluid," Computational Thermal Sciences, 6, 273-283. https://doi.org/10.1615/.2014011207.

Bagai, S., and Nishad, C., 2012, "Effect of Variable Viscosity on Free Convection Heat Transfer over a Non-isothermal Body of Arbitrary Shape in a Non-Newtonian Fluid Saturated Porous Medium with Inter- nal Heat Generation," Transport in Porous Media, 94, 277-288. https://doi.org/10.1007/s11242-012-0004-2.

Chaves, C.A., Lamas, W.D.Q., Do Patrocinio Nunes, L.E.N., Camargo, J.R., and Grandinetti, F.J., 2015, "Notes on Steady Natural Convection Heat Transfer by Double Diffusion From a Heated Cylinder Buried in a Saturated Porous Media," AMSE Journal of Heat Transfer, 137, 074501. http://dx.doi.org/10.1115/1.4029878.

Christopher, R.H., and Middleman, S., 1965, "Power-law Flow through a Packed Tube," I \& EC Fundamentals, 4, 422-426.

https://doi.org/10.1021/i160016a011.

Dharmadhikari, R.V., and Kale, D.D., 1985, "Flow of Non-Newtonian Fluids through Porous Media," Chemical Engineering Science, 40, 527528.

https://doi.org/10.1016/0009-2509(85)85113-7.

El-Arabawy, H.A.M., 2009, "Soret and Dufour Effects on Natural Convection Flow past a Vertical Surface in a Porous Medium with Variable Surface Temperature," Journal of Mathematics and Statistics, 3, 190198.

https://doi.org/10.3844/jmssp.2009.190.198.

El Haroui, M., Sriti, M., Achemlal, D., and Flilihi, E., 2017, "Prediction of Thermosolutal Convection in a Porous Medium with Soret-Dufour and Chemical Reaction Effects," Computational Thermal Science, 9, 383393.

https://doi.org/10.1615/ComputThermalScien.2017019817.

Ibrahim, F.S., Hady, F.M., Abdel-Gaied, S.M., and Eid, M.R., 2010, "Influence of Chemical Reaction on Heat and Mass Transfer of NonNewtonian Fluid with Yield Stress by Free Convection from Vertical Surface in Porous Medium Considering Soret Effect," Applied Mathematics and Mechanics, 31, 675-684.

https://doi.org/10.1007/s10483-010-1302-9.

Kairi, R., and RamReddy, C., 2015, "The Effect of Melting on Mixed Convection Heat and Mass Transfer in Non-Newtonian Nanofluid Saturated in Porous Medium," Frontiers in Heat and Mass Transfer, 6, 6. http://dx.doi.org/10.5098/hmt.6.6.

Lai, F., and Kulacki, F.A., 1990, "The Effect of Variable Viscosity on Convective Heat Transfer along a Vertical Surface in a Saturated Porous Medium," International Journal of Heat and Mass Transfer, 33, 10281031.

https://doi.org/10.1016/0017-9310(90)90084-8.

Moorthy, M.B.K., and Senthilvadivu, K., 2011, "Effect of Variable Viscosity on Convective Heat and Mass Transfer by Natural Convection from Vertical Surface in Porous Medium," WSEAS Transactions on Mathematics, 10, 751-759.

https://dl.acm.org/citation.cfm?id=2037118.

Nield, D.A., and Bejan, A., 2017, Convection in Porous Media, 5th ed., Springer.

http://dx.doi.org/10.1007/978-3-319-49562-0.

Pullepu, B., Sambath, P., Selva Rani, M., Chamkha, A.J., and Viswanathan, K., 2016, "Numerical Solutions of Free Convective Flow from a Vertical Cone with Mass Transfer under the Influence of Chemical Reaction and Heat Generation/Absorption in the Presence of UWT/UWC," Journal of Applied Fluid Mechanics, 9, 343-356. https://doi.org/10.18869/acadpub.jafm.68.224.24062.

Srinivasacharya, D., and Swamy Reddy, G., 2016, "Chemical Reaction and Radiation Effects on Mixed Convection Heat and Mass Transfer over a Vertical Plate in Power-law Fluid Saturated Porous Medium," Journal 
of the Egyptian Mathematical Society, 24, 108-115. https://doi.org/10.1016/j.joems.2014.10.001.

Thohura, S., Mamun Molla, M., and Sarker, M.M.A., 2016, "Natural Convection of Non-Newtonian Fluid along a Vertical Thin Cylinder using Modified Power-law Model," AIP Conference Proceedings, International Conference on Mechanical Engineering, 1754 - 040021, Dhaka,
Bangladesh.

https://doi.org/10.1063/1.4958381.

Trevisan, O.V., and Bejan, A., 1990, "Combined Heat and Mass Transfer by Natural Convection in a Porous Medium," Advance Heat Transfer, 20, 315-352.

https://doi.org/10.1016/S0065-2717(08)70029-7. 